\title{
STUDI LITERATUR PENDUGAAN NILAI KONDUKTIVITAS HIDRAULIK DENGAN MENGGUNAKAN DATA UJI HIDRAULIK LAPANGAN DAN DATA LOGING GEOTENIK
}

\author{
Tedy Agung CAHYADI ${ }^{1}$, Irwan ISKANDAR ${ }^{2)}$, Sudarto NOTOSISWOYO ${ }^{3)}$, Lilik Eko WIDOD04) \\ 1) Mahasiswa Pasca Sarjana Program Rekayasa Pertambangan ITB \\ 2) Staf Pengajar Program Rekayasa Pertambangan ITB \\ e-mail : tedyagungc.students.itb@gmail.com
}

\begin{abstract}
Abstrak
Konduktivitas hidraulik merupakan parameter yang sangat penting dalam pemodelan aliran airtanah. Parameter tersebut dapat diambil melalui pengujian packer test dan slug test. Mahalnya operasional pelaksanaan pengujian tersebut, memberikan dampak minimnya data kondutivitas hidraulik di lapangan. Konduktivitas hidraulik pada batuan yang terkekarkan memiliki kompleksitas (derajad heterogenitas dan anisotropi) yang lebih tinggi dibandingkan dengan konduktivitas hidraulik pada batuan sedimen. Untuk mengatasi minimnya data konduktivitas hidraulik, dalam studi literature ini akan dilakukan cara prediksi nilai konduktivitas hidraulik dengan menggunakan pendekatan metode HC-System. HC-System merupakan metode empirik yang melibatkan data-data geoteknik menduga nilai konduktivitas hidraulik di daerah yang tidak ada data pengukuran (terbatas pada titik pengukuran geoteknik). Data geoteknik tersebut terdiri dari Rock Quality Designation (RQD), Lithology Permeability Index (LPI), Depth Index (DI), and Gouge Content Index.
\end{abstract}

Kata kunci: konduktivitas hidraulik, HC-system

\section{PENDAHULUAN}

Dalam pemodelan aliran airtanah membutuhkan parameter akuifer yang cukup lengkap, di mana salah satunya adalah nilai konduktivitas hidraulik (K). Untuk memperoleh nilai $\mathrm{K}$ tersebut dapat dilakukan dengan cara berbagai macam pengujian lapangan tergantung kebutuhan, diantaranya seperti slug test, pumping test dan packer test. Selain itu untuk memperoleh nilai $\mathrm{K}$, dapat pula dikerjakan di laboratorium dengan menggunakan constant head permeability. Pengujian tersebut sangat diperlukan khususnya bagi perusahaan yang akan mengelola air dalam tahap perencanaan pada kegiatan permodelan airtanah khususnya dalam industri pertambangan. Kondisi ekonomi Indonesia saat ini yang semakin melemah, mengakibatkan lesunya kondisi industri pertambangan mineral dan batubara. Sehingga untuk memenuhi kebutuhan data lapangan yang bisa representative akibat terbatasnya biaya, dibutuhkan pendekatan baru dalam memperoleh informasi nilai $\mathrm{K}$ dengan data lapangan yang terbatas. Adanya studi literature ini sangat penting, untuk memberikan wawasan tambahan khususnya kepada hidrogeologist tambang dalam memprediksi nilai $\mathrm{K}$ berdasarkan data yang terbatas.

Hsu at al (2009), telah mengembangkan sebuah klasifikasi batuan menggunakan indeksindeks yang disusun dari data hasil investigasi geoteknik dan pengamatan struktur. Indeksindeks tersebut antara lain Rock Quality Designation (RQD), Depth Index (DI), Gouge Content Designation (GCD), dan Lithologi Permeability Index (LPI). Nilai konduktivitas hidraulik merupakan gabungan dari $R Q D, D I, G C D$ dan $L P I$. Komparasi antara hasil data pengujian hidraulik lapangan yang terbatas dibandingkan data RQD, DI, GCD, dan LPI akan menghasilkan persamaan numerik yang menggambarkan sebaran nilai K pada lokasi yang diteliliti. Penelitian tersebut telah digunakan oleh beberapa peneliti Indonesia untuk memprediksi nilai $\mathrm{K}$ berdasarkan data loging geoteknik, diantaranya oleh Iskandar at al (2014). 


\section{METODOLOGI}

Tahapan dalam penelitian yang dikerjakan oleh Hsu at al (2009) dan Iskandar at al (2014) dirangkum seperti bagan alir Gambar 1. Namun, disini penulis menambahkan bukan hanya uji packer test yang bisa menghasilkan nilai $\mathrm{K}$, melainkan menambah uji slug test . Uji slug test ini lebih banyak digunakan untuk tambang yang ada di Indonesia karena biayanya lebih murah, khususnya sebagian besar tambang batubara dan sisanya tambang bijih. Dengan filosofi bahwa dalam pengujian slug test memilih target litologi yang akan dicari nilai permeabiltasnya, maka peranan slug test dianggap bisa menghasilkan kinerja yang sama seperti hanya packer test.

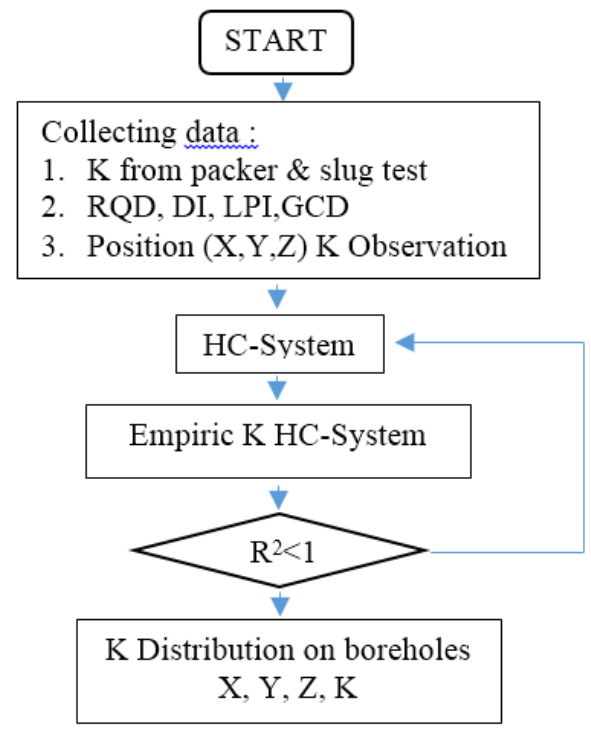

Gambar 1. Diagram Alir Distribusi K pada Data Loging Geoteknik

Packer test (Gambar 2.a) merupakan salah satu metode tes akuifer untuk mendapatkan nilai konduktivitas hidraulik pada batuan terkekarkan. Singhal dan Gupta (1999), telah menggunakan metode ini untuk mengetahui nilai permeabilitas pada media terkekarkan. Tes dilakukan pada bore hole pada interval kedalaman tertentu dengan target akuifer yang ingin diketahui nilai konduktivitas hidraulik. Interval kedalaman target kemudian diisolasi dengan bantuan dua material penyekat (selubung karet) yang dapat digembungkan dan dikempiskan. Tambang yang menggunakan metode packer test biasanya merupakan tambang bijih.

Slug test (Gambar 2.b) merupakan uji akuifer dengan mengalirkan air pada pipa instalasi sampai ketinggian tertentu, dari ketinggian air tersebut dicatat waktu dan elevasi penurunan muka air tanah dalam pipa sampai diperoleh kondisi yang steady. Hvorselv (1951), menyampaikan bahwa metode ini biasanya ditentukan terlebih dahulu target formasi di mana tempat dibuatnya screen yang akan dicari nilai permeabilitinya. Metode ini biasanya dipakai untuk tambang batubara dan bijih. Karena biayanya yang relative lebih murah dibandingkan packer test, maka metode ini sering dipakai baik di tambang mineral maupun batubara.

Rock Quality Designation (RQD). Dari sudut pandang hidrogeologi, rekahan mencerminkan kemampuan suatu formasi untuk mengalirkan air melalui rekahan itu sendiri. Oleh karena itu, derajat kerekahan dapat dipandang sebagai suatu faktor untuk mengetahui permeabilitas massa batuan. Deere dkk. (1967) telah mengembangkan sebuah indeks untuk mengukur pengaruh karakteristik rekahan terhadap permeabilitas yang disebut indeks $R Q D$. Nilai $R Q D$ didefinisikan sebagai panjang kumulatif core dengan ukuran lebih panjang dari $100 \mathrm{~mm}$ dalam satu run dibagi dengan total panjang core run. Formulasi untuk $R Q D$ adalah sebagai berikut : 
$R Q D=\frac{\sum \text { Panjang core }>100 \mathrm{~mm}}{\text { total panjang corerun, } \mathrm{mm}} \times 100 \%=\frac{R s}{R t} \times 100 \%$

Indeks Kedalaman (DI). Kedalaman dapat dianggap sebagai faktor untuk mengukur permebilitas. Besar permebilitas batuan berkurang dengan bertambahnya kedalaman (Lee et al., 1993, Singhal et al., 1999). Hal ini disebabkan berkurangnya aperture dan spasi rekahan akibat tekanan. Indeks yang melibatkan kedalaman dalam penentuan permeabilitas adalah depth index yang dapat diperoleh dengan formulasi berikut :

$D I=1-\frac{L c}{L T}$

dimana $L T$ adalah total panjang borehole; $L C$ adalah kedalaman tengah interval uji packer test .

Lithology Permeability Index (LPI). Jenis litologi sangat mempengaruhi besar permeabilitas. Karakteristik litologi seperti besar butir, tekstur, warna, kandungan mineral berbeda antara satu jenis litologi dengan litologi yang lain. Sebagai contoh, batuan sedimen dengan besar butir yang besar akan mempunyai nilai permebilitas lebih besar daripada batuan yang berbutir kecil. Besar LPI untuk masing-masing batuan dapat dilihat pada Tabel 1.

Gouge Content Designation (GCD). Jika rekahan mengandung isian seperti gouge, kemampuan rekahan untuk mengalirkan air akan berkurang sehingga menurunkan nilai permeabilitas. Untuk mengukur pengaruh material isian terhadap permeabilitas, indeks yang disebut sebagai GCD didefinisikan dengan persamaan berikut :

$G C D=\frac{R G}{R T-R S}$.

dimana $R G$ adalah total panjang isian, $R S$ adalah panjang kumulatif potongan inti core yang lebih panjang dari $100 \mathrm{~mm}$ dalam satu run dan $R T$ adalah total panjang inti core (RT).

Nilai $H C$ didapatkan dengan persamaan berikut :

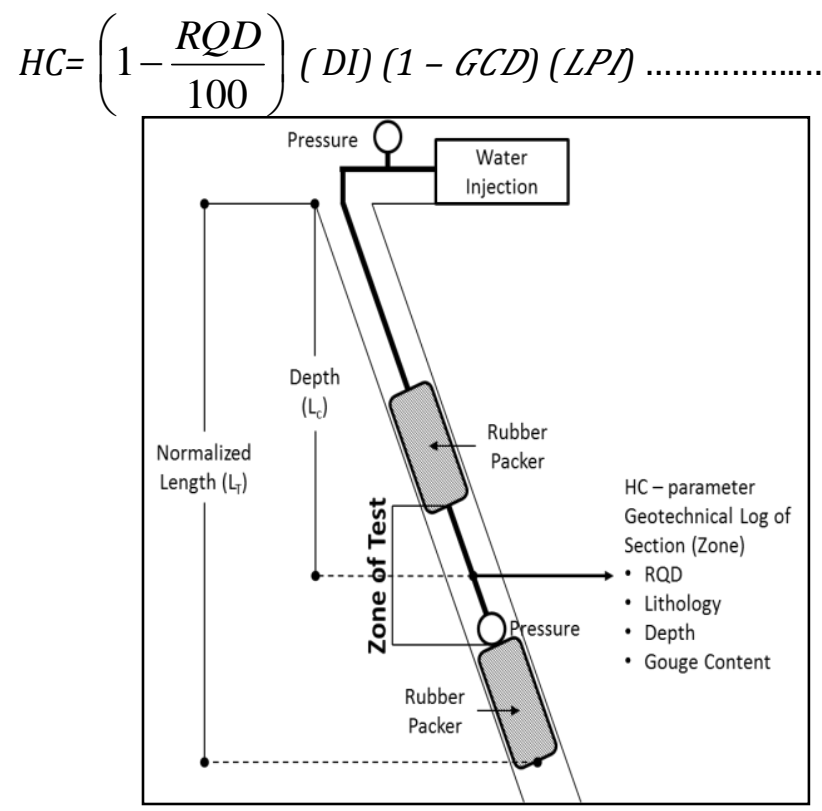

Gambar 2.a Packer test (kiri), dikutip dari Iskandar at al (2014)

2.b Slug test (kanan), dikutip dari Fetter (2001) 
Tabel 1. Indek LPI Berdasarkan Litologi (dikutip dari Hsu et al, 2009)

\begin{tabular}{|c|c|c|c|c|c|c|}
\hline \multirow[b]{2}{*}{ Lithology } & \multicolumn{4}{|c|}{ Hydraulic Conductivity $(\mathrm{m} / \mathrm{s})$} & \multirow{2}{*}{$\begin{array}{l}\text { Range } \\
\text { of } \\
\text { Rating }\end{array}$} & \multirow{2}{*}{$\begin{array}{l}\text { Suggested } \\
\text { Rating }\end{array}$} \\
\hline & Reference" & Reference $^{2}$ & Reference $^{3}$ & $\mathrm{~K}_{\text {atcaser }}$ & & \\
\hline Sandstone & $10^{-6}-10^{-9}$ & $10^{-7}-10^{3}$ & $10^{7}-10^{-5}$ & $10^{-73}$ & $0.8-1.0$ & 1 \\
\hline $\begin{array}{c}\text { Silty } \\
\text { Sandstone }\end{array}$ & - & 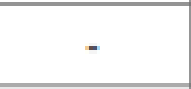 & - & - & $0.9-1.0$ & 0.95 \\
\hline $\begin{array}{l}\text { Argillaccous } \\
\text { Sandstone }\end{array}$ & - & - & - & - & $0.8-0.9$ & 0.85 \\
\hline $\begin{array}{l}\text { S.S. } \\
\text { interbedded } \\
\text { with some } \\
\text { Sh. }\end{array}$ & - & - & - & - & $0.7-0.8$ & 0.75 \\
\hline $\begin{array}{l}\text { Alternations } \\
\text { of S.S \& Sh. }\end{array}$ & - & - & - & - & $0.6-0.7$ & 0.65 \\
\hline $\begin{array}{l}\text { Sh. } \\
\text { Interbedded } \\
\text { with some } \\
\text { S.S. }\end{array}$ & - & - & - & - & $0.5-0.7$ & 0.6 \\
\hline $\begin{array}{l}\text { Alternations } \\
\text { of S.S \& } \\
\text { Mudstone }\end{array}$ & - & - & - & - & $0.5-0.6$ & 0.55 \\
\hline Dolomite & $\begin{array}{l}10^{6}-10^{-} \\
\text {Dos }\end{array}$ & $10^{7}-10^{-105}$ & $10^{-6}-10^{-10}$ & $10^{-5}$ & $0.6-0.8$ & 0.7 \\
\hline Limestone & $10^{6}-10^{-}$ & $10^{-7}-10^{-9}$ & $10^{-9}-10^{10}$ & $10^{-5}$ & $0.6-0.8$ & 0.7 \\
\hline Shale & $10_{12}^{-16}-10^{\circ}$ & $10^{-10}-10^{-13}$ & - & $10^{-105}$ & $0.4-0.6$ & 0.5 \\
\hline Sandy Shale & - & - & - & & $0.5-0.6$ & 0.6 \\
\hline Siltstone & $10_{12}^{-10}-10$ & - & - & $10^{-11}$ & $0.2-0.4$ & 0.3 \\
\hline $\begin{array}{c}\text { Sandy } \\
\text { Siltstone }\end{array}$ & - & - & - & & $0.3-0.4$ & 0.4 \\
\hline $\begin{array}{l}\text { Argillaceous } \\
\text { Siltstone }\end{array}$ & - & - & - & & $0.2-0.3$ & 0.2 \\
\hline Claystone & - & $10^{-9}-10^{-13}$ & - & $10^{-11}$ & $0.2-0.4$ & 0.3 \\
\hline Mudstone & - & - & - & & $0.2-0.4$ & 0.2 \\
\hline $\begin{array}{c}\text { Sandy } \\
\text { Mudstone }\end{array}$ & - & - & - & & $0.3-0.4$ & 0.4 \\
\hline $\begin{array}{c}\text { Silty } \\
\text { Mudstone }\end{array}$ & - & - & - & & $0.2-0.3$ & 0.3 \\
\hline Granite & - & - & $10^{-11}-10^{-}$ & $10^{-11.5}$ & $0.1-0.2$ & 0.15 \\
\hline Basalt & $\begin{array}{c}10^{6}-10^{-} \\
\text {bos }\end{array}$ & $10^{-10}-10^{-13}$ & - & $10^{-11.3}$ & $0.1-0.2$ & 0.15 \\
\hline
\end{tabular}

1B.B.S. Singhal and Gupta (1999). ${ }^{2}$ Karlbeinz Spitz and Joanna Moreno (1996) ${ }^{3}$ Bear (1972)

\section{HASIL DAN PEMBAHASAN}

Hsu at al (2009), melakukan penelitian penentuan konduktivitas hidraulik pada batuan sedimen yaitu sandstone dan shale. Kondisi lokasi penelitian juga terdapat struktur yang menyebabkan kondisi hasil coring memiliki nilai RQD sangat rendah, dan untuk lokasi yang tidak dilewati 
struktur memiliki nilai RQD yang tinggi. Pengujian packer test dilakukan pada 26 titik target, sehingga diperoleh nilai kondiktivitas hidraulik pada daerah tersebut. Dari ke 26 titik pengukuran tersebut, 22 data digunakan untuk mencari persamaan numerik berdasarkan parameter RQD, LPI, DI, GCD pada lokasi pengujian packer test. Sedangkan 4 data digunakan untuk melakukan validasi terhadap model numerik yang dihasilkan. Tabel 2 dan Gambar 3.a menunjukkan hubungan antara data loging geoteknik dan uji packer test diplotkan dengan persamaan power sehingga memperoleh persamaan numerik $\mathrm{K}$ yang digunakan untuk menguji korelasinya. Hubungan antara hasil model dan hasil observasi dapat dilihat pada Gambar 3.b.

Tabel 2. Hasil HC System (dikutip dari Hsu at al, 2009)

\begin{tabular}{|c|c|c|c|c|c|c|c|}
\hline Boreholes & $\begin{array}{c}\text { Test } \\
\text { intervals } \\
(\mathrm{m})\end{array}$ & $\begin{array}{c}1- \\
\text { RQD/100 }\end{array}$ & DI & 1 -GCD & LPI & HC & $\begin{array}{c}\text { K } \\
(\mathrm{m} / \mathrm{s})\end{array}$ \\
\hline \multirow{5}{*}{ HB-94-01 } & $34.7-36.3$ & 0.094 & 0.677 & 1.000 & 1.000 & 0.0635 & $7.06 \mathrm{E}-08$ \\
\cline { 2 - 8 } & $36.4-38.0$ & 0.438 & 0.662 & 1.000 & 1.000 & 0.2895 & $1.64 \mathrm{E}-06$ \\
\cline { 2 - 8 } & $56.7-58.3$ & 0.063 & 0.477 & 1.000 & 0.950 & 0.0283 & $1.53 \mathrm{E}-08$ \\
\cline { 2 - 8 } & $74.6-76.2$ & 0.500 & 0.315 & 1.000 & 0.400 & 0.0629 & $5.30 \mathrm{E}-08$ \\
\cline { 2 - 8 } & $77.2-78.8$ & 0.010 & 0.291 & 1.000 & 0.400 & 0.0012 & $4.22 \mathrm{E}-10$ \\
\cline { 2 - 8 } & $82.6-84.2$ & 0.125 & 0.242 & 1.000 & 0.400 & 0.0121 & $2.31 \mathrm{E}-09$ \\
\cline { 2 - 8 } & $90.2-91.8$ & 0.010 & 0.173 & 1.000 & 0.400 & 0.0007 & $2.86 \mathrm{E}-10$ \\
\cline { 2 - 8 } & $94.2-95.8$ & 0.500 & 0.136 & 1.000 & 0.400 & 0.0273 & $4.53 \mathrm{E}-09$ \\
\hline \multirow{5}{*}{ HB-95-01 } & $99.0-101.9$ & 0.345 & 0.598 & 0.200 & 0.400 & 0.0165 & $9.80 \mathrm{E}-09$ \\
\cline { 2 - 8 } & $117.2-120.1$ & 0.690 & 0.526 & 1.000 & 0.850 & 0.3081 & $9.76 \mathrm{E}-07$ \\
\cline { 2 - 8 } & $133.2-136.1$ & 0.724 & 0.461 & 0.286 & 1.000 & 0.0954 & $4.68 \mathrm{E}-08$ \\
\hline & $88.6-91.4$ & 0.071 & 0.743 & 1.000 & 0.600 & 0.0318 & $1.56 \mathrm{E}-07$ \\
\cline { 2 - 8 } & $96.0-99.2$ & 0.031 & 0.721 & 1.000 & 0.600 & 0.0135 & $2.42 \mathrm{E}-08$ \\
\cline { 2 - 8 } & $118.5-121.7$ & 0.219 & 0.657 & 0.071 & 0.700 & 0.0072 & $1.36 \mathrm{E}-09$ \\
\cline { 2 - 8 } & $134.8-138.0$ & 0.344 & 0.610 & 0.727 & 0.700 & 0.1068 & $1.17 \mathrm{E}-07$ \\
\cline { 2 - 8 } & $154.8-158.0$ & 0.938 & 0.553 & 0.103 & 0.700 & 0.0376 & $1.99 \mathrm{E}-08$ \\
\cline { 2 - 8 } & $173.0-176.2$ & 0.938 & 0.501 & 0.103 & 0.700 & 0.0340 & $9.08 \mathrm{E}-09$ \\
\cline { 2 - 8 } & $189.8-193.0$ & 0.594 & 0.453 & 1.000 & 0.700 & 0.1883 & $1.01 \mathrm{E}-06$ \\
\cline { 2 - 8 } & $196.6-199.8$ & 0.563 & 0.434 & 0.500 & 1.000 & 0.1220 & $6.00 \mathrm{E}-08$ \\
\cline { 2 - 8 } & $213.2-216.0$ & 0.679 & 0.387 & 1.000 & 1.000 & 0.2625 & $4.54 \mathrm{E}-07$ \\
\cline { 2 - 8 } & $249.0-251.8$ & 0.393 & 0.285 & 0.091 & 0.700 & 0.0071 & $4.03 \mathrm{E}-09$ \\
\cline { 2 - 8 } & $272.0-274.8$ & 0.214 & 0.219 & 1.000 & 0.700 & 0.0328 & $3.36 \mathrm{E}-08$ \\
\hline
\end{tabular}
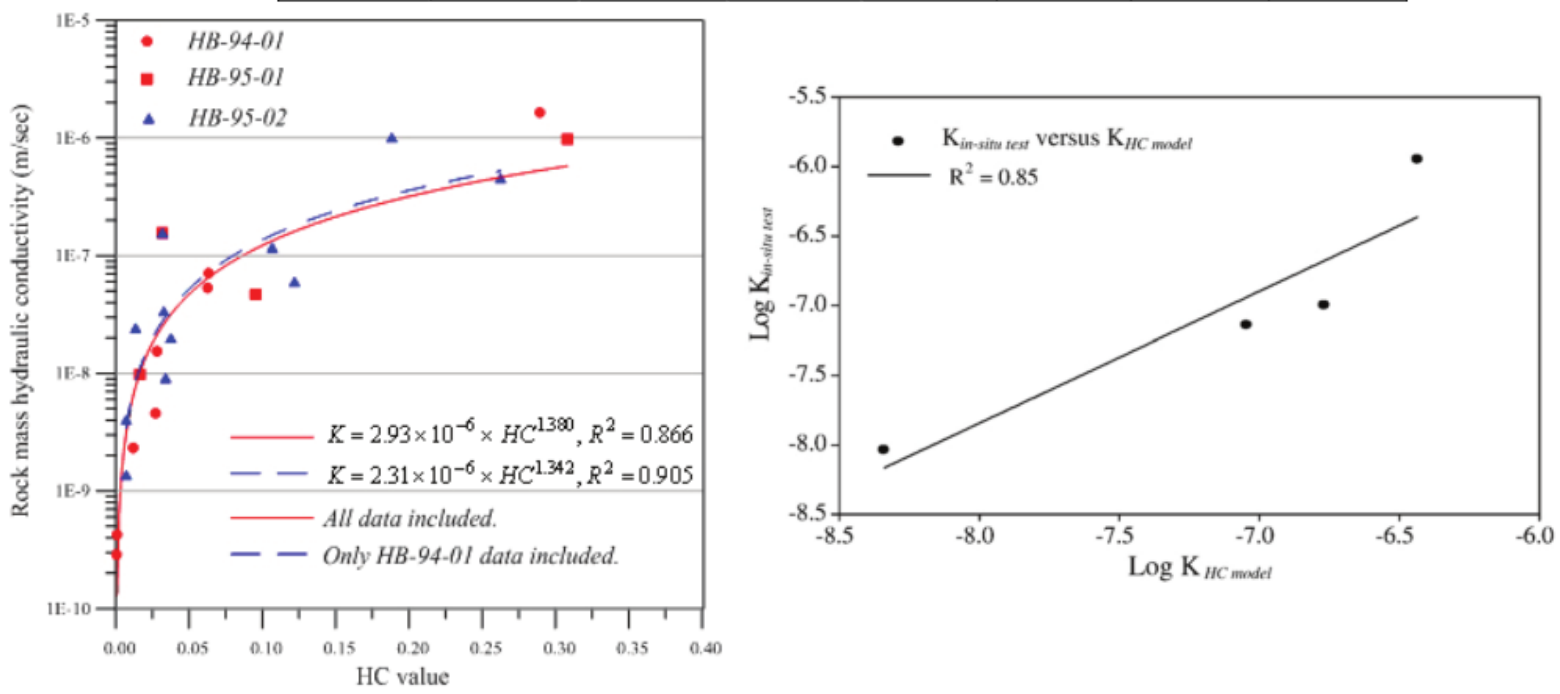

Gambar 3.a Hubungan HC Indek dan Data Uji Packer test (kiri), dikutip dari Hsu at al (2009)

3.b Korelasi K hasil model dan K Uji Packer test (kanan), dikutip dari Hsu at al (2009)

Iskandar at al (2014), melakukan hal yang sama seperti yang dikerjakan oleh Hsu at al (2009). Perbedaannya adalah kondisi lubang bor yang ada pada penelitian ini memiliki kemiringan tertentu, sedangkan Hsu kondisi lubang bornya cendurung vertikal. Sehingga dalam hal 
pendeskripsian Depth Indek (DI) sifatnya hanya melakukan transformasi menjadi tegak lurus, seperti yang ada di Gambar 2.b. Kondisi litologi yang ada di lokasi penelitian adalah siltstone, carbonaceues shale dan dolomite. Tabel 3 dan Gambar 4 menunjukkan bahwa Iskandar at al (2014), menggunakan 16 data uji packer test untuk menyusun model numerik, yang dianggap mewakili persebaran nilai K pada daerah tersebut.

Tabel 3. Hasil HC System (dikutip dari Iskandar at al, 2014)

\begin{tabular}{|c|c|c|c|c|c|c|c|c|}
\hline $\begin{array}{c}\text { Hole } \\
\text { ID }\end{array}$ & Lithology & $\begin{array}{l}\text { Point of Test } \\
\text { Zone (m) }\end{array}$ & $\begin{array}{l}\text { Total Depth } \\
\text { (m) }\end{array}$ & 1-(RQD/100) & DI & GCD & LPI & $\mathrm{HC}$ \\
\hline \multirow{4}{*}{002} & Dolostone & 57.00 & 114.50 & 0.85 & 0.50 & 0.10 & 0.7 & 0.30 \\
\hline & Dolostone & 68.00 & 114.50 & 0.99 & 0.41 & 0.10 & 0.7 & 0.28 \\
\hline & Dolostone & 79.00 & 114.50 & 0.96 & 0.31 & 0.10 & 0.7 & 0.21 \\
\hline & Dolostone & 91.00 & 114.50 & 0.78 & 0.21 & 0.23 & 0.7 & 0.11 \\
\hline \multirow[t]{3}{*}{003} & $\begin{array}{l}\text { Carbonaceous } \\
\text { Shale }\end{array}$ & 103.00 & 120.00 & 0.79 & 0.14 & 0.10 & 0.7 & 0.07 \\
\hline & Dolostone & 113.00 & 120.00 & 0.73 & 0.06 & 0.55 & 0.7 & 0.04 \\
\hline & Siltsone & 131.50 & 209.00 & 0.95 & 0.37 & 0.01 & 0.5 & 0.15 \\
\hline \multirow[t]{2}{*}{146} & $\begin{array}{l}\text { Carbonaceous } \\
\text { Shale }\end{array}$ & 172.50 & 209.00 & 0.73 & 0.17 & 0.01 & 0.4 & 0.05 \\
\hline & Dolostone & 197.00 & 209.00 & 0.82 & 0.06 & 0.10 & 0.7 & 0.03 \\
\hline \multirow{2}{*}{088} & $\begin{array}{l}\text { Carbonaceous } \\
\text { Shale }\end{array}$ & 121.00 & 180.70 & 0.62 & 0.33 & 0.10 & 0.6 & 0.11 \\
\hline & $\begin{array}{l}\text { Carbonaceous } \\
\text { Shale }\end{array}$ & 133.00 & 180.70 & 0.84 & 0.26 & 0.01 & 0.5 & 0.10 \\
\hline \multirow{2}{*}{102} & $\begin{array}{l}\text { Carbonaceous } \\
\text { Shale }\end{array}$ & 202.00 & 292.60 & 0.93 & 0.31 & 0.01 & 0.5 & 0.12 \\
\hline & $\begin{array}{l}\text { Carbonaceous } \\
\text { Shale }\end{array}$ & 270.50 & 292.60 & 0.96 & 0.08 & 0.01 & 0.5 & 0.03 \\
\hline 025 & Siltsone & 35.00 & 160.60 & 1.00 & 0.78 & 0.05 & 0.4 & 0.28 \\
\hline 067 & Dolostone & 216.40 & 220.80 & 0.60 & 0.02 & 0.01 & 0.7 & 0.01 \\
\hline
\end{tabular}

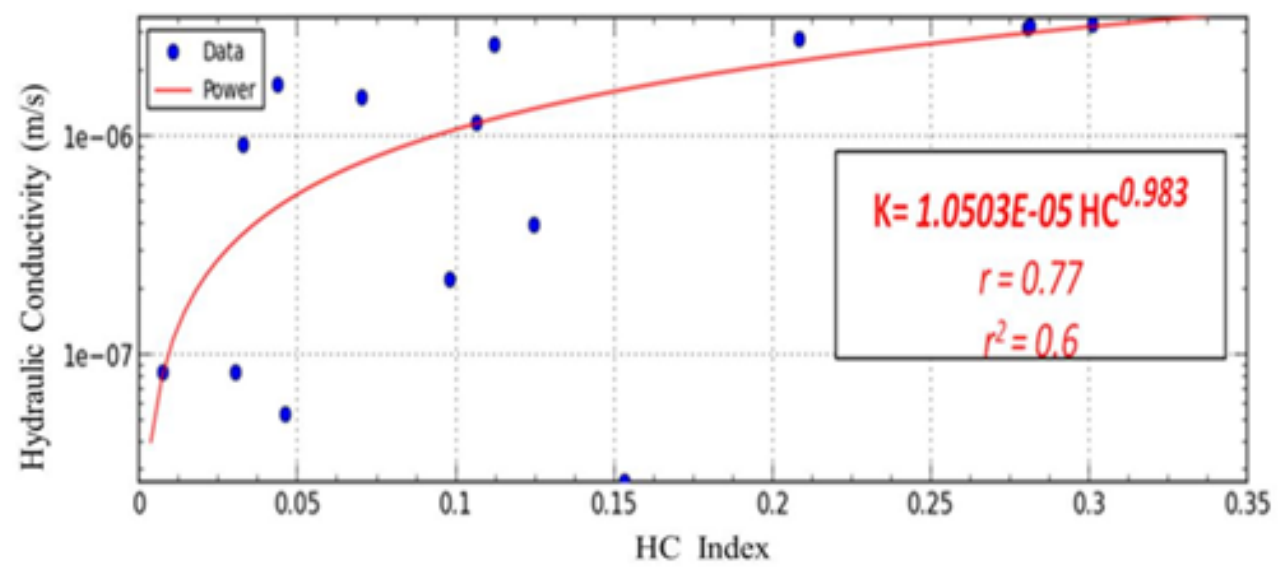

Gambar 4. Hubungan HC Indek dan Data Uji Packer Test, dikutip dari Iskandar at al, (2014)

Persamaan numerik antara data geoteknik yaitu berupa RQD, DI, LPI dan GCD dengan data observasi pengujian packer test di lapangan, menunjukkan bahwa adanya perbedaan hasil koefisien determinasi yang berbeda. Hsu et al (2009) menghasilkan $\mathrm{R}^{2}$ yang cukup tinggi sebesar 0,86 , sedangkan Iskandar memperoleh nilai $R_{2}=0,6$ relative rendah. Salah satu perbedaannya karena pengaruh dalam pendeskripsian Depth Indek (DI), di mana Hsu menggunakan data bor yang cenderung vertikal, sedangkan Iskandar menggunakan transformasi dari bor yang miring menjadi menjadi vertikal. 
Dari studi literatur Hsu at al (2009) dan Iskandar et al (2014), diperoleh gambaran bahwa dengan data pengujian lapangan yang terbatas, mampu memprediksi nilai $\mathrm{K}$ di tempat lainnya berdasarkan pendekatan data geoteknik. Sehingga data bor yang telah dimiliki oleh perusahaan dapat digambarkan kondisi parameter akuifernya berdasarkan pendekatan metode HC-System. Hal ini sangat sesuai dengan kondisi ekonomi saat ini, sehingga perlu melakukan terobosan agar dapat memaksimalkan informasi khususnya data hidrogeologi di lapangan.

\section{KESIMPULAN}

Berdasarkan studi literatur menurut Hsu et al (2009) dan Iskandar et al (2014) dapat ditarik kesimpulan :

1. Penggunaan metode HC-System dapat diterapkan untuk memperoleh nilai konduktivitas hidraulik pada uji permeabilitas yang terbatas.

2. Mencoba menggunakan data slug test untuk mencari data $\mathrm{K}$ observasi jika uji packer test dianggap mahal.

3. Distribusi $\mathrm{K}$ dengan menggunakan data loging geoteknik akan memberikan gambaran bahwa sebaran K di alam sifatnya adalah heterogen.

\section{UCAPAN TERIMAKASIH}

Penulis mengucapkan terimakasih kepada Lab Hidrogeologi Tambang ITB yang telah memberikan dukungan dalam penulisan paper ini.

\section{DAFTAR PUSTAKA}

1. Bear, J. (1972) : Dynamics of Fluids in Porous Media, American Elsevier Publication Co., New York

2. Deere, D. U., Hendron, A. J., Patton, F. D., Cording, E. J. (1967): Design of Surface and Near Surface Construction In Rock, Proceedings of 8th U.S. Symposium. Rock Mechanics, AIME, pp. 237-302, New York

3. Fetter, C.W., (2001) : Applied Hydrogeology $4^{\text {th }}$ edition, Upper Saddle River, N.J., PrenticeHall

4. Hsu M.H., Chiou L.B., Lin G.F., Ku C.Y., (2009) : An empirical model for estimating hydraulic conductivity of highly disturbed clastic sedimentary rocks in Taiwan, Engineering Geology 109 213-223

5. Hvorselv (1951) : Time lag and soil permeability in groundwater observation, US Army Corps of engineer Waterway Experimentation Station, Bulletin 36

6. Iskandar I., Wibowo A., Casanova B., Notosiswoyo S., (2014): A 3D Model of Hydraulic Conductivity Distribution of Fractured Rocks Using Packer test Result and Geotechnical Log, International Symposium on Earth Science and Technology, University of Kyushu, Japan

7. Lee C.H., Farmer I. (1993) : Fluid Flow In Discontinuous Rocks, Chapman \& Hall, London, UK

8. Singhal B.B.S., Gupta, R.P. (1999) : Applied Hydrogeology of Fractured Rocks, Kluwer Academic Publishers, The Netherlands, $400 \mathrm{p}$

9. Spitz, K., and Moreno, J. (1996). "A practical guide to groundwater and solute transport modeling," John Wiley, New York, 480 p. 